\title{
Adoption of Water Saving Irrigation Techniques for Sustainable Rice Production in Bangladesh
}

\author{
M. R. Rahman ", S. H. Bulbul \\ Institute of Environmental Science, Ecology and Biodiversity Research Laboratory, University of Rajshahi, Bangladesh
}

Copyright (c) 2015 Horizon Research Publishing All rights reserved.

\begin{abstract}
This study explore socio-economic characters' which leads farmers to adoption of Alternate Wetting and Drying (AWD) in the farmers' field of two major drought prone areas of Bangladesh for rice cultivation. AWD is an irrigation regime where the producer allows the rice field to dry intermittently during the rice life cycle rather than having the field continuously submerged. In previous studies AWD has been found to reduce water usage by from $20-70 \%$ and to reduce methane emissions by over $50 \%$ as compared to rice produced under continuous flooding. In 2012, a survey of 60 farmers was conducted in four rice-producing areas in Bangladesh to investigate farmer implementation of AWD and NF irrigation. Thirty sample farmers from the Capasia union of Gazipur district were selected in the site where the AWD irrigation techniques are being practiced. Similarly, 30 other sample farmers were selected from the same Union of Gazipur district where AWD is not practiced but where continuous irrigation is practiced. Similarly thirty sample farmers from Godagary union of Rajshahi district were selected in the site where the AWD irrigation techniques are being practiced and 30 other sample farmers were selected from the same Union Rajshahi district where AWD is not practiced but where continuous irrigation is practiced. The data were collected through direct interview with the help of pre-designed questionnaire in 2012. A brief introduction regarding the nature and objectives of the study was given to each respondent before interview. All the collected qualitative and quantities data were analyzed in accordance with the objectives of the study so as to answer the issues involved in the study. As the dependent variables are dichotomous (zero, one), a logit regression model can be applied. The study shows that significant issues were identified that need to be considered generally to improve adoption at the farmers' level and that would eventually enable mass adoption. The study revealed that farm size, education of household head, and contact with extension agents, water scarcity and dissemination through demonstration were the variables that had significant impact on the adoption of AWD. So if contact with extension workers could be increased and the farmers could be shown the use of AWD techniques through field demonstration then the adoption rates can be increased.
\end{abstract}

Keywords Adoption, Alternate Wetting and Drying (WAID), Irrigation, Boro Rice

\section{Introduction}

Water is not only essential to sustain life, but it also plays an integral role in ecosystem support, economic development, community well-being, and cultural values. As the International Year of Freshwater, 2003 is an opportunity to focus on the role of water as a precious and finite resource that we must use carefully.

In 30 years, the earth's population may be 8 billion people and the number people dependent on rice for food may equal 5 billion. Feeding them will require a massive increase in global rice production, and which thus will increase demand for water. More than $75 \%$ of the rice supply comes from 79 million ha of irrigated land. Recently, the scarcity of, and competition for, water has been increasing worldwide. By 2025, the per capita available water resources in Asia are expected to decline by $15-54$ percent compared with 1990 availability [1]. Despite the constraints of water scarcity, rice production and productivity must rise in order to address the growing demand for rice driven largely by population growth and rapid economic development in Asia. Producing more rice with less water is therefore a formidable challenge for achieving food, economic, social, and water security for the region [2].

Water is an essential input for modern agriculture, and more use of irrigation water, especially groundwater, has contributed to manifold increases in crop productivity in Bangladesh. Ground water irrigation has probably been the mostdramatic development in Bangladeshi agriculture in the past 25 years. Not many countries in the world, if any, are as dependent upon ground water as Bangladesh is. Indeed, the contribution of ground water to total irrigated area was $77 \%$ in 2006-07. However, in some areas, especially the northwestern part of the country, groundwater tables have been declining rapidly, and this decline threatens the economic viability of future rice production.

Rice is the most important food crop in Asia [3], 
however, it requires most water. In fact, the majority of the world's rice is being produced under flooded, so-called lowland conditions. Rice grown under traditional practices in the Asian tropics and subtropics requires between $700-1500 \mathrm{~mm}$ of water per cropping season depending on soil texture [4]. However, this conventional water management method leads to a high amount of surface runoff, seepage, and percolation that can account for between $50-80 \%$ of the total water input [5].

In many Asian countries, per capita availability declined by $40-60 \%$ between 1955 and 1990 , and is expected to decline further by $15-54 \%$ over the next 35 years [6]. The main reasons are diverse and location specific, but include increasing population growth, increasing urban and industrial demand, and decreasing availability because of pollution (chemicals, salts, silts) and resource depletion. In agriculture, the situation is aggravated by the dramatically increasing costs for irrigation development over the past decades. Because of the combined increasing demand for food with increasing scarcity of water, rice producers face three major challenges: (i) to save water; (ii) to increase productivity; and (iii) to produce more rice with less water [7]. The most appropriate strategies to adopt will vary over time and space and will have to be designed carefully with the involvement of the farmers, but will need to be resolutely forward-looking and perhaps revolutionary. Identifying the policies, management practices and technologies needed at farm, system and basin level will require a multi-disciplinary approach [8].

The sustainability concept argues for a holistic and balanced approach to life where economic prosperity, nature conservation and social justice are given equal weight in any long term strategies of development (Government of Western Australia, 2003). New definitions of sustainability are constantly emerging, however they all share common aspects. The Research Group on the Global Futures provides an array of definitions for sustainability but concludes that most definitions have three aspects in common. These are living within limits; understanding the interconnections between the economy, society and the environment; and equitable distribution of resources and opportunities (Research Group on Global Futures 2005).

The sustainable use of water would require the maintenance of a desired flow of benefits to a particular group or place, undiminished over time. Benefits involve cultural values and issues, and are a function of the stock of, and the demand for, water, both of which vary with technology and population. Demands for water include not just what people need, but what they want. This latter demand is potentially much larger than minimum basic needs. A better definition would incorporate the requirement that benefits to all current users be maintained, without reducing benefits to other users, including natural ecosystems.

Technological progress in rice cultivation is crucial for sustaining food security in Bangladesh. AWD is an irrigation regime where the producer allows the rice field to dry intermittently during the rice life-cycle rather than having the field continuously submerged. In previous studies AWD is found to reduce water usage by from $20-70 \%$ and to reduce methane emissions by almost $50 \%$ as compared to rice produced under continuous flooding, which was certified by the Intergovernmental Panel on Climate Change (IPCC). However, several thousand farmers throughout the Bangladesh now practice alternate wet dry (AWD) and non-flooded (NF) irrigation during the vegetative stage of crop development.

In order to achieve a large-scale spread and adoption of AWD, at least in regions where water scarcity poses a threat to sustain and further improve rice cultivation, a number of constraints and issues at national, regional and local levels have to be overcome as suggested by the findings [9].

This paper presents the results of a survey that examined farmer adoption with AWDI and NF irrigation in Bangladesh. Farmer implementation of these water saving practices is compared for the cases vs. traditional cultivation methods.

\section{Methodology}

\subsection{Selection of the Samples and Sampling Technique}

Thirty sample farmers from the Rainonda village of Capasia union of Gazipur district, Bangladesh were selected in the site where the AWD irrigation techniques are being practiced. Similarly, 30 other sample farmers were selected from the Chorboria of the same Union of Gazipur district, Bangladesh where AWD is not practiced but where continuous irrigation is practiced. Similarly thirty sample farmers from Chapal Village of Godagary union of Rajshahi district, Bangladesh were selected in the site where the AWD irrigation techniques are being practiced and 30 other sample farmers were selected from the Naraonpur village of Godagry Union Rajshahi district where AWD is not practiced but where continuous irrigation is practiced.

\subsection{Data Collection Instruments}

Keeping in view the expected outcomes of the assessment survey, appropriate data collection instruments were prepared. Interviewed schedule was prepared to collect primary data from the farmers. The schedule was pre-tested and modified accordingly before final use. The interviewed schedule was prepared in such a way that all aspects associated with the objectives could be included. In the pre-test survey, attention was paid to identify any new information, which was not included in the draft schedule. Then some parts of draft schedule were improved, rearranged and modified in the light of the experience gained from the field. Lastly, the final interview schedule was prepared to collect the information. The farming of the questions in interviewed schedule was done in such a way, that they could be easily understood by the informants and their responses could be quicker. Besides, leading questions 
were avoided; questions pertaining to the private and personal life of the respondents were also not included in the schedule. The questions were properly structured, so that even the most reluctant information's could have no hesitation in passing the necessary information. The questionnaire included the following items of information needed for the analysis.

- Identification of the sample farmer.

- Farm size and tenure status of sample farmer.

- Use of material inputs for cultivation of rice.

- Yield, outputs, cost and returns of producing of rice.

- Problems faced by the rice growing farmers and suggested solution.

\subsection{Collection of Data}

The study is based on a set of field level primary data. The data were collected through direct interview with the help of pre-designed questionnaire in 2012. A brief introduction regarding the nature and objectives of the study was given to each respondent before interview. The respondents were given assurance that all information would be kept confidential, be used exclusively for research purpose and study will not affect their interest in any adverse way, rather it might produce some benefits to general mass in course of time. Before interviewing, the selected respondents were contacted so that they could be interviewed according to their convenient time. Then the questions were asked systematically in a very simple manner with necessary explanation. After completion of each interview, the interviewed schedule was checked to be sure that information to each of the items had been properly recorded. Any items overlooked or found contradictory were corrected in the second time visit.

\subsection{Processing and Analysis of Data}

After collecting requisite data, they were processed and analyzed with a view to achieve the objectives of the study. The primary data were collected from the rice growing farmers and then data were processed (edited and coded) and computerized using MS excel. All the collected qualitative and quantities data were analyzed in accordance with the objectives of the study so as to answer the issues involved in the study.

\subsection{Analytical Techniques}

Both tabular and statistical techniques were used to analyze the collected data. Tabular technique was followed to find out the crude association or differences between variables and outputs. Tabular technique is a well known and widely used technique to show the result of farm management study because it is simple, convenient and very easy to understand. The data and information so collected were recorded to tabular form which included classification of tables into meaningful results by some statistical measures like the sum, average, percentage etc. to show the relationship between /among the selected variables. Tabular analysis was done to address the objectives.

\subsection{Logistic Regression Model}

As the dependent variables are dichotomous (zero, one), a logit regression model can be applied. Logit model are widely applied statistical techniques in which the probability of a dichotomous outcome (for e.g adopter or non-adopter) is related to a set of explanatory variables that are hypothesized to influence the outcome [10].

[11] pointed out that the logistic distribution (logit) has got advantage over the others in the analysis of dichotomous outcome variable in that it is extremely flexible and easily used model from mathematical point of view and results in a meaningful interpretation. The parameter estimates of the model were asymptotically consistent and efficient. The standardized coefficients correspond to the beta-coefficients in the ordinary least squares regression models. The binary logistic model does not make the assumption of linearity between dependent and independent variables and does not assume homoscedasticity [12]. Another advantage of using the logit model is relatively easy to compute and interpret. Hence, the logistic model is selected for this study. The probability that a farmer will adopt at least one improved rice variety was postulated as a function of some socioeconomic, demographic characteristic and institutional factors. Therefore, the cumulative logistic probability model is econometrically specified as follows:

$$
\mathrm{P}_{\mathrm{i}}=\mathrm{F}\left(\mathrm{Z}_{\mathrm{i}}\right)=\mathrm{F}\left(\propto+\sum \beta \mathrm{X}_{i}\right)=\frac{1}{1+e^{-Z_{I}}}
$$

Where,

$\mathrm{Pi}$ is the probability that a farmer will adopt rice AWD irrigation technology or not given $\mathrm{Xi}$;

e denotes the base of natural logarithms, which is approximately equal to 2.718 ;

$\mathrm{Xi}$ represents the ith explanatory variables and $\propto$ And $\beta$ are parameters to be estimated. [11] pointed out that the logit model could be written in terms of the odds and log of odds, which enables one to understand the interpretation of the coefficients. The odds ratio implies the ratio of the probability ( $\mathrm{Pi}$ ) that a farmer adopt to the probability (1-Pi) that the farmer is non-adopter.

$$
\left(1-\mathrm{P}_{\mathrm{i}}\right)=\frac{1}{1+e^{Z_{l}}}
$$

Therefore

$$
\frac{P_{i}}{1-p_{i}}=\frac{1+e^{Z_{I}}}{1+e^{-Z_{I}}}=e^{Z_{I}}
$$

The natural $\log$ of equation (3), will give:

$$
\begin{gathered}
\mathrm{L}_{\mathrm{i}}=\left(\frac{P_{i}}{1-P_{i}}\right) \\
\propto \propto+\beta_{1} \mathrm{X}_{1}+\beta_{2} \mathrm{X}_{2}+\beta_{3} \mathrm{X}_{3}+\ldots \ldots+\beta_{\mathrm{n}} \mathrm{X}_{\mathrm{n}}
\end{gathered}
$$


If the disturbance term $\left(\mathrm{U}_{\mathrm{i}}\right)$ is taken into account, the logit model becomes:

$$
\mathrm{L}_{\mathrm{i}}=\alpha+\sum_{i=1}^{7} \beta_{i} \mathrm{X}_{i}+U_{i}
$$

Equation (3) was estimated by maximum likelihood method. This procedure does not require assumptions of normality or homoscedasticity of errors in predictor variables. This analysis was carried using STATA Version 11. The variables used in logit model are described in the following (Table 1)

\section{Results and Discussion}

The mean farm size of the samples from both sites ranged from 0.66 to 0.68 hectare (Table 2). The samples have more or less similar socioeconomic characteristics as shown by the similar magnitudes of their age, farm size, family size and level of education. In total, $70 \%$ and $76 \%$ of the non-adopters of Gazipur and Rajshahi district did not receive any training on AWD. On average, farmers from AWD and Non- AWD have annual incomes of about 1,26,734 and 1,02216 taka respectively. In the field survey, farmers were able to discern water scarcity as a problem during the Boro season in both study regions. Also, among the control group of farmers, $82 \%$ confirmed that water scarcity occurs during the Boro season. The problem of water scarcity is particularly severe in Rajshahi Division, the high number of interviewees (39\%) who identified groundwater shortages as their main problem of irrigation..

Table 1. Description of the Variables used in the Logit Model.

\begin{tabular}{|c|c|c|}
\hline Variable & Type & Measurement \\
\hline \multicolumn{3}{|c|}{ Dependent variable } \\
\hline $\mathrm{Li}$ & Dummy & 1 if farmer has adopted AWD irrigation technology, Otherwise 0. \\
\hline \multicolumn{3}{|r|}{ Explanatory variables } \\
\hline Experience & Continuous & Experience of the household head (years) \\
\hline Education & Dummy & $\begin{array}{c}\text { Formal education of the household head. 1, if more than primary level } 0 \text {, } \\
\text { otherwise }\end{array}$ \\
\hline Household size & Continuous & Total family member (No. of persons) per households \\
\hline Farm size & Continuous & Amount of land under cultivation (ha) \\
\hline Non-farm income & Dummy & Engagement in non-farm income generating activities 1,0 otherwise 0 \\
\hline Contact extension agent & Dummy & $\begin{array}{l}\text { Contact with extension agent by the respondent, } 1 \text { if farmer Contact with } \\
\text { extension agents, } 0 \text { otherwise }\end{array}$ \\
\hline Land ownership & Dummy & Ownership of the land, 1 if the land is owned, 0 otherwise \\
\hline Farmers' training & Dummy & 1, If farmers attend in AWD training. \\
\hline Water scarcity & Dummy & 1, if farmers face water scarcity \\
\hline Rice crop area & Dummy & 1 , if rice crop area is more than non-rice crop area \\
\hline Land quality or type & Dummy & If land is plain, then 1 , otherwise 0 \\
\hline Regional Dummy & Dummy & 1 , if Gazipur, otherwise, 0 \\
\hline Dissemination through demonstration & Continuous & No. of times of demonstration, farmer observed. \\
\hline
\end{tabular}

Table 2. Basic Farm and Household Characteristics of Sampled AWD Users and Non-AWD User Farmers for Both Sites.

\begin{tabular}{|c|c|c|c|c|}
\hline & \multicolumn{2}{|c|}{ Rajshahi } & \multicolumn{2}{|c|}{ Gazipur } \\
\hline & AWD & NON-AWD & AWD & NON-AWD \\
\hline Number of sample & 30 & 30 & 30 & 30 \\
\hline Mean farm size (hectare) & 0.66 & 0.68 & 0.69 & 0.67 \\
\hline Mean household size & 4.2 & 4.3 & 4.1 & 4.0 \\
\hline Mean age of farmers (Years) & 35.42 & 39.51 & 37.38 & 40.26 \\
\hline Mean education of the farmer & 9.1 & 8.5 & 8.98 & 7.70 \\
\hline Farmers' training (\% of yes) & 67 & 30 & 56 & 24 \\
\hline Extension facilities ( $\%$ of yes) & 88 & 52 & 82 & 32 \\
\hline Water scarcity & 86 & 60 & 75 & 52 \\
\hline Proportion of Non-farm income share & 0.72 & 0.41 & 0.88 & 0.52 \\
\hline$\%$ of rice crop area & 82 & 65 & 94 & 51 \\
\hline$\%$ of active members in the family & 56 & 52 & 65 & 59 \\
\hline $\begin{array}{l}\text { Satisfaction about the quality of the extension service (\% of satisfied } \\
\text { households) }\end{array}$ & 32 & 12 & 26 & 11 \\
\hline Dissemination through demonstration (No. of imes) & 1.5 & 0.6 & 1.1 & 0.5 \\
\hline Land quality type (good $=1$, otherwise 0$)$ & 50 & 32 & 46 & 36 \\
\hline Member of any social organization (\%) & 73 & 56 & 75 & 52 \\
\hline Total household income (Tk) & 128,810 & 99,078 & 124,658 & 105,354 \\
\hline
\end{tabular}


Table 3. Socio-Economic Factors Influencing Adoption of AWD Technology

\begin{tabular}{|c|c|c|c|c|}
\hline Variable & Notation & Coefficient & Standard error & $\mathrm{P}>|\mathrm{z}|$ \\
\hline Constant & & 8.909 & 3.043 & 0.053 \\
\hline Experience & $\mathrm{X}_{1}$ & 0.119 & 0.077 & 0.113 \\
\hline Education of household head & $\mathrm{X}_{2}$ & $1.844^{* *}$ & 0.777 & 0.018 \\
\hline Farm size & $\mathrm{X}_{3}$ & $3.388^{*}$ & 0.407 & 0.065 \\
\hline Contact with extension agents & $\mathrm{X}_{4}$ & $2.341^{* * *}$ & 0.856 & 0.004 \\
\hline Farmers' training & $\mathrm{X}_{5}$ & 1.631 & 0.955 & 0.320 \\
\hline Water scarcity & $\mathrm{X}_{6}$ & $0.243^{*}$ & 0.102 & 0.023 \\
\hline Rice crop area (1, if rice crop area is more than non-rice \\
crop area) & $\mathrm{X}_{7}$ & $0.573^{*}$ & 0.303 & 0.080 \\
\hline Dissemination through demonstration & $\mathrm{X}_{8}$ & $0.639^{*}$ & 0.2910 & 0.028 \\
\hline Land quality or type (plain =1, otherwise 0) & $\mathrm{X}_{9}$ & $0.363^{* * *}$ & 0.127 & 0.004 \\
\hline Regional Dummy (1, if Gazipur, otherwise, 0$)$ & $\mathrm{X}_{10}$ & 1.070 & 0.665 & 0.112 \\
\hline
\end{tabular}

Source: Field survey 2012,

Note: Negelkerke $\mathrm{R}^{2}=0.63$, ${ }^{*}$ Significant at $10 \%$ level of significance, ${ }^{* *}$ Significant at $5 \%$ level of significance, ${ }^{* * *}$ Significant at $1 \%$ level of significanc

The main purpose of this study is to explore the important factors that influence farmers' decisions to adopt Alternative Wetting and drying (AWD) technology. To this end, we performed Logit regression analysis. The results of the Logit regression model estimating factors influencing adoption of AWD technology are presented in (Table 3). The fit of the data was statistically significant at $(\mathrm{P}<0.001)$, While the Nagelkerke $R^{2}=0.63$. These results shows that the overall model is significant and the explanatory variables used in the model are collectively able to explain the farmers' decisions regarding the adoption of AWD technology. The independent variables included in the model have been described here.

\subsection{Experience}

Normally aged farmers are experienced than young farmers. Though it is not significant but during field study, the observation was experienced farmers who were cultivating rice since 20 years or more, more interested and progressive to receive the AWD technology. The coefficient of farming experience $0.119(\mathrm{P}<0.10)$ indicates that, holding other variables constant, if years of farming experience increase by a unit, on the average, the logit of the odds in favor of AWD irrigation technology sole increase by 0.119 units. The effect of farming experience on adoption of AWD irrigation technology could be due to the farmer's managerial ability, sincerity and understanding of the potentials of the AWD irrigation technology as a result of many years of farming.

\subsection{Education}

The result shows that the adoption of AWD significantly increased $(p<0.01)$ as the years of education increase, which implies educated farmers are more motivated to adopt AWD technology. Exposure to education may increase farmers' ability to obtain, process, and use information relevant to the adoption of AWD technology. Education thus is thought to increase the probability that a farmer will adopt AWD technology. [13] reported similar findings revealing that exposure to education increases farmer's ability to obtain process and use information relevant to adopt IRM for increased yield. The coefficient of education was expected positive to decrease risk aversion behavior and increase the rate of adoption.

\subsection{Farm Size}

Farm size is an indicator of wealth and it can be thought of as a proxy for social status and influence within a community. A larger farm size is expected to be positively associated with the decision to adopt AWD technology. Farm size is another important factor that is statistically significant at $1 \%$ level of significance. It indicates that larger farm size is more likely to adopt AWD irrigation technology. [14] stated that, the positive and significant coefficient of farm size indicates its positive influence in adoption new technology. They said it may be because the farm size is a surrogate for a large number of factors such as size of wealth, access to credit, capacity to bear risk, access to information and other factors.

Farm size can also encourage farmers to intensify agricultural production, in which case, a larger farm size is expected to be negatively related to the adoption of improved maize technology. [15] found that too small and too large farm size decreases farmers' efficiency. [16] found that a farm size between 7 and 12 acres is the most efficient (overall efficiency) in the contest of Bangladesh agriculture.

\subsection{Farmers' Training}

Training sessions play a key role for successfully disseminating any new technology to farmers and assuring later adoption. It was hypothesized that attending in a training program about irrigation would have strong positive impact on the likelihood of AWD adoption. But it did not 
happen in our research.

Most farmers have received training very recently. From the non adopters who received training, mostly, explained that they did not receive adequate training or did not understand AWD. All types of farmers frequently criticized about the duration of training which is too short (maximum half an hour). On the other hand, most training sessions took place only once. Even most field officers agreed that to really understand AWD, more sessions would be necessary. Another major factor for not adopting the technology is connected to the timing of the training. Of the farmers, who did not adopt AWD, some of them criticized that the training starts too late in the season. When training was received in February or March, they were not able to effectively apply AWD anymore during that season. [17] stated about training approach that was found in the field was a one-off training session that was given to unorganized groups on several irrigation matters i.e. on field days. Despite the advantages of raising awareness of AWD quickly and cost effectively and among many farmers, this kind of training does not support experience-based learning. In our case, it is also true that training does not necessarily increase adoption rates of AWD.

\subsection{Water Scarcity}

The result shows that farmers, who face water scarcity, adopt AWD technology. It was found that $86 \%$ farmers at Gazipur and $75 \%$ farmers at Rajshahi region faced water scarcity. Either they have financial problem, so that they are not or their plots are very far from the water source. On the other hand, in most cases, non adopters are owners of shallow tube wells or they can get water supply very easily. So, the scarcity of water is not only about the water source but also about the cost of irrigation. [17] mentioned that farmers and pump-owners of the northern region of Bangladesh consider that high irrigation prices are a problem for irrigation. They also pointed that though there is a physical water scarcity; water is rather considered to be an economically scarce resource in the region. The problem of water scarcity in Bangladesh very often, is basically linked to the chronically deficient electricity supply. Practically all DTWs and many STWs are run with electricity. Bottlenecks in power supply therefore form a central obstacle for farmers in obtaining irrigation water in time.

For some farmers the water situation is so drastic that they are considering discontinuing rice cultivation in the future. Many adopter farmers mentioned that farmers have to cope with an erratic electricity supply. In the northern region, continuous electricity supply sometimes lasts for just 10 minutes, while the overall electricity supply might last for only three hours each day. The lack of electricity is considered as the foremost problem of rice cultivation in both study regions by farmers

In contrast to electricity, fuel presents a much more secure but expensive source of energy for irrigation. Farmers also explained that fuel is sometimes hard to come by as distances to markets are far and fuel is not always available.

\subsection{Area Allocated to Rice}

Farmers, who allocate their land mostly for rice, are more conscious to adopt AWD technology. It may be due to the fact that if they fail to receive expected production, they have to suffer for the whole year. Therefore, to get sufficient amount of water at appropriate time, they want to adopt any new technology so that they can be ensured about water.

\subsection{Contact with Extension Agents}

Agricultural extension services provided by the Ministry of Agriculture are the major source of agricultural information in the study area. It is hypothesized that contact with extension workers will increase farmers' likelihood of adopting AWD technologies. The organizations involved in extension and development activities deploy staff at local level. This field staff must be able to take on the responsibility of conveying the knowledge about AWD and to convince water users to actually apply the new technology. The role of extension staff was also confirmed by the responses of farmers during the survey. It has been found that farmers who have frequent contacts with extension agents had higher probability to adopt AWD irrigation technology than those who are not connected with extension agents. When asked whose advice they trusted most, close to half of the farmers who did not receive training on AWD generally rely on extension staff when they have problems.

The result also suggested that in adoption of AWD irrigation technologycould be motivated by frequent contacts with extension agents. Extension agents popularizes AWD irrigation technology adoption by making farms exchange idea, experiences, and makes it cheaper to source information, knowledge and skills in order to enable farmers to improve their livelihood.

\subsection{Land Quality}

Land is also an important factor to adopt AWD technology. During the study period, it was observed that farmers those who have plot in plain land, would like to learn the technology and interested to adopt compared to sloppy lands. It may be the reason that in plain land, water would stand that is not possible at the sloppy land.

\subsection{Dissemination through Demonstration Plots}

The adoption process of AWD in Bangladesh is still in its early stages. Most of the farmers applied the technology for the first time in the 2010 or 2011. A large share of them started after conducting AWD demonstrations instructed by BRRI and DAE. In light of our results above, insights from studies about the flexible implementation of AWD (such as this one) need to be effectively disseminated to rice producers through extension and outreach programs. 
For demonstration purposes, progressive leader farmers usually implemented an AWD-plot alongside a conventionally irrigated plot. This enabled farmers to test AWD on a small plot and to directly compare respective costs and benefits. The prerequisites for the plot itself were that it had to be close to the road, easily accessible and near a pumping system. The rice field is used as the learning tool as it combines both learning sessions in the field and follow-up support [14]. Demonstration plots were often set up during Farmer Field Days and ended by organizing local crop-cutting ceremonies during harvesting, inviting the farmers of the area to join the AWD validation. Thus, the information on the results of the testing are passed on to a larger audience. The disseminating organizations usually supplied farmers with "demonstration packages" that included different field inputs and AWD pipes. Several goals are pursued with the set up of demonstration plots. Farmers can test the new technology through hands-on-experience and can learn how to use it. Using the "model-farmer" approach, normally small-scale farmers would follow the lead farmers, having the benefit of observing the application of AWD. Demonstration plots help to inform farmers, to start discussions about the technology and to help spread the news to other groups and villages. The result shows that the approach with demonstration plots was very successful as it allowed farmers to acquire an understanding of the technology. There is also group approach to disseminate AWD technologies. Farmers within the groups seem to be encouraged to share experiences with the new packages provided to farmers often consisted inputs such as seeds, fertilizers, pesticides and tools to measure the water level (AWD tube), depending on the resources of the organizations.

However, extension staff mostly expressed doubts that AWD - as a knowledge intensive technology - will spread based on farmers' observations only. The desired "snow-ball effect", of neighboring farmers taking over the technology from the model farmers might not work as desired.

\section{Conclusions}

Based on the results achieved so far at national, regional and local levels, the national relevance of the technology and its applicability for farmers will be assessed, together with the effectiveness of specific dissemination approaches and perspectives for a process of up-scaling and out-scaling. Along with it a view on the future of AWD will be presented as a water-saving technology in irrigated rice production in Bangladesh.

The findings outlined in this experiment are a rough approximation of the factors that favor or hinder the adoption of AWD. Nevertheless, significant issues were identified that need to be considered generally to improve adoption at the farmers' level and that would eventually enable mass adoption. The study revealed that farm size, education of household head, and contact with extension agents, water scarcity and dissemination through demonstration were the variables that had significant impact on the adoption of AWD. So if contact with extension workers could be increased and/or the farmers could be shown the use of AWD techniques through field demonstration then the adoption rates can be increased.

Extension programs that provide general irrigation information and specific information regarding AWD can potentially encourage further adoption of this irrigation technique. As mentioned above the public benefit of adopting water-conserving technologies such as AWD should be emphasized in these extension programs. Water conservation benefits can potentially be realized if local government agencies as well as international agencies (e.g., IRRI), continue to provide education and training about the latest research on AWD and other water-conserving technologies to local extension personnel, field technicians, and as well as farmers.

\section{REFERENCES}

[1] L.C. Guerra, S.I. Bhuiyan, T.P. Tuong, R. Barker. Producing more rice with less water from irrigated systems. SWIM Paper 5. Colombo International Irrigation Management Institute, Sri Lanka. 1998.

[2] T. Facon. Improving the irrigation service to farmers: a key in participatory irrigation management. Paper presented at the Asian Productivity organization seminar on organizational change for participatory irrigation management, 23-27 October 2000, Manila, Philippines. 2000 .

[3] IRRI (International Rice Research Institute). Rice almanac, second edition. IRRI, Los Baños, Philippines, 181 pp. 1997.

[4] S.I. Bhuiyan. Water management in relation to crop production: case study on rice. Outlook on Agriculture Vol. 21, 293-299, 1992.

[5] P.K. Sharma. Effect of periodic moisture stress on water to use efficiency in wet land rice. Oryza. Vol. 26, 252-257, 1989.

[6] P. H. Gleick, (Ed). Water in Crisis: A Guide to the World's Fresh Water Resources. Oxford University Press, New York, USA, 473 pp. 1993.

[7] B.A.M. Bouman, T.P. Tuong. Field water management to save water and increase its productivity in irrigated lowland rice. Agric. Water Manag. Vol. 49, 11-30, 2001.

[8] M.R. Rahman, S. H. Bulbul. Effect of Alternate Wetting and Drying (AWD) Irrigation for Boro Rice Cultivation in Bangladesh. Agriculture, Forestry and Fisheries. Vol. 3, No. 2, 2014, pp. 86-92. doi: 10.11648/j.aff.20140302.16

[9] S.H. Bulbul, M.R. Rahman. Sustainable Water Use Efficiency for Rice Cultivation in Rajshahi of Bangladesh. American Journal of Agriculture and Forestry. Vol. 2, No. 4, 2014, pp. 146-153. doi: 10.11648/j.ajaf.20140204.17

[10] R.P., Neupane, K.R. Sharma, G.B. Thapa. Adoption of 
agroforestry in the hills of Nepal: a logistic regression analysis. Agricultural Systems Vol. 72, No.177-196, 2000.

[11] D.W. Hosmer, S. Lemeshew. Applied Survival Analysis: Regression Modeling of Time to Event Data. New York: Wiley, 1989.

[12] CIMMYT, The Adoption of Agricultural Technology: A Guide for Survey Design. Londres, Mexico: Economics Programme, International Maize and Wheat Improvement Centre. 1993.

[13] M.R. Roderick, G. Palis, F.R.M. Ruben, B. Lampayan, A.M. Bouman. Impact of the alternate wetting and drying (AWD) water-saving irrigation technique: Evidence from rice producers in the Philippines. Journal homepage: www.elsevier.com/ locate/foodpol, Food Policy Vol. 36, 280-288, 2011.

[14] G. Feder, R.E. Just, and D. Zilberman. 1985. Adoption of agricultural innovations in developing countries: a survey. Econ. Dev. Cult. Change, Vol. 33, 255-297.

[15] A. Hoque, 'Farm size and economic allocative efficiency in
Bangladesh agriculture', Applied Economics, Vol. 20 No. 10, $1353-68,1988$.

[16] A.Z.M. Haq. Some issues of extension contact on rice productivity in Bangladesh. Proceedings of the annual conference on HR at the modern workplace 2011 Dec 16-17. SDM Institute for Management Development, Mysore, India, 2011.

[17] E.C. Kuerschner, T . Henschel, H. Juelich, E. Leineweber, C. Paul. Water Saving in Rice Production- Dissemination, Adoption and Short Term Impacts of Alternate Wetting and Drying (AWD) in Bangladesh, Postgraduate Studies on International Cooperation, Study commissioned by the Advisory Service on Agricultural Research for Development of German Technical Cooperation (GTZ-BEAF) in collaboration with the International Rice Research Institute (IRRI), SLE Publication Series - S241, 2010.

[18] FAO (Food and Agriculture Organization). The State of Food and Agriculture, Food and Agriculture Organization of the United Nations Viale delle Terme di Caracalla 00153 Rome, Italy, 2007. 